\title{
Logistics Systems Engineer - Interdisciplinary Competence Model for Modern Education
}

\author{
http://dx.doi.org/10.3991/ijep.v5i2.4578 \\ Tarvo Niine and Ott Koppel \\ Tallinn University of Technology, Tallinn, Estonia
}

\begin{abstract}
Logistics is an interdisciplinary field of study. Modern logisticians need to integrate business management and administration skills with technology design, IT systems and other engineering fields. However, based on research of university curricula and competence standards in logistics, the engineering aspect is not represented to full potential. There are some treatments of logistician competences which relate to engineering, but not a modernized one with widespread recognition. This paper aims to explain the situation from the conceptual development point of view and suggests a competence profile for "logistics system engineer", which introduces the viewpoint of systems engineering into logistics. For that purpose, the paper analyses requirements of various topical competence models and merges the introductory competences of systems engineering into logistics. In current interpretation, logistics systems engineering view integrates networks, technologies and ICT, process and service design and offers broader interdisciplinary approach. Another term suitable for this field would be intelligent logistics. The practical implication of such a competence profile is to utilize it in curriculum development and also present it as an occupational standard. The academic relevance of such concept is to offer a specific way to differentiate education in logistics.
\end{abstract}

Index Terms-competence models, curriculum development, logistics engineering, systems engineering.

\section{INTRODUCTION}

Logistics is by nature an interdisciplinary field of study. In terms of engineering, logistics topics range from optimization of order delivery, inventory and distribution networks to dealing with inherent physical properties of cargo and designing transit, warehousing, handling and supporting IT-systems. From the traditional viewpoint of business administration, logistics is viewed as a function in service of company strategy that aims to provide the right products at the right time in the right place as consistently as possible. There is of course substantial common ground in these approaches, but also differences, which means the most suitable approach in logistics is interdisciplinary education. The aspects of both natural and social sciences are heavily linked in logistics also in studying the broad view of transport economics, such as in analyzing cargo flows, travel patterns and regulatory systems, and in logistics network design.

More specifically, modern logistics needs to be treated as a cross-functional integration concept that is aimed at coordinating business functions priorities, analyzing supply and demand realities and outlooks, developing processes that would better match existing demand with available supply and cooperating with suppliers for improvements to material and information flows.
However, based on research of university curricula, it is observed that the field of logistics education does not include engineering aspects to enough extent. This is both in terms of technologies as well as the systematic nature of engineering thinking. Large proportion of logistics curricula are focused on business administration with only selected engineering topics touched, usually focusing on case studies of implementation benefits rather than how to specifically design, develop such technologies and to reengineer processes to accommodate with the changes. In terms of logistics system design and underlying thought processes, the approach could often benefit from being more systematic.

Similar gap can be observed on the level of competence models in logistics. There are numerous treatments relating to engineering elements but not a modern central and recognized one. This paper observes the problem closely, aims to explain the situation from concept development viewpoint and suggests a competence profile for a position "logistics system engineer", which introduces viewpoints of "systems engineering" (SE) into logistics, fills one gap in modern logistics education and is recommended to be applied by academia in practice.

This paper reviews literature on logistics engineering, followed by what has been found in terms of competences in SE. The methodology of this study is founded on analyzing a selection of models of logistics competences from SE models viewpoint in order to identify the gaps and then design a profile of logistics systems engineer to fill these gaps. Once the model is introduced and commented upon, the authors' conclude with brief discussion of limitations and outlining future research. But before going into details of competence models, some explanations of background setting are in order.

\section{BACKGROUND - LOGISTICS EVOLUTION}

A selection of prominent keywords of logistics development over the last half century are integration, total cost optimization, responsiveness and general increase in relevance. Nevertheless, it is not only practical environment that alters the understanding of logistics, but also theoretical reflection about how concepts support practice and what aspects should be covered by existing constructs. A point often quoted was made by P. Drucker in 1962, which described logistics as "economy's dark continent" and a "low-grade nuisance" [1]. The society has gone a long way since - the "continent" today is far from being dark and logistics is seen as major value generator rather than tedious cost element. It could be paraphrased that through the decades, logistics has grown from garage level into office and onwards to the level of executive directors. Along that growth, little has been lost, 
PAPER

but conceptual complexity has increased. The field of logistics today is more complex in both technology and management components than ever before.

This has much changed the way logistics is taught and what competences are expected from a specialist. The traditional concept still 50 years ago was "physical distribution management". The focus was on process capabilities and control, optimal routes and schedules, all topics of engineering flavor. In the 1970s, the term "logistics" became popular aiming to deal with a larger set of topics than the father-concept. The "systems view" integrated more and more topics and functions into physical distribution treatments. The ideas of total system cost and cost trade-off management were born and remain at the core of logistics ever since.

In the next step it, inbound and outbound logistics became integrated and it was clear the old concept "physical distribution management" was redundant and misleading. The evolution of logistics continued, being much influenced in the 1980s by the value chain concept of M. Porter [2]. As a result, similarly to past, yet a new concept emerged - supply chain management (SCM). This new idea drew more attention towards value creation across conventional business functions - such as purchasing, logistics, manufacturing and sales - and towards managing business relationships in a supply chain in more dimensions than previously implied by logistics.

Today, the practical relations between the fields of logistics and SCM are unclear in workplace, in classrooms and in academic debate. Having previously researched these conceptual relations, it appears logistics is in relatively higher need of more specific and agreed formulation than SCM [3]. While SCM is understood without substantial contradictions, the academia has not reached an agreement on the content and scope of logistics and the situation is vaguer than in the 1980's. Some authors have stepped on the SCM "gravy train" and have ceased to emphasize logistics per se, while others attempt to define distinct difference. Therefore it is not surprising that there is effectively only little standardization in logistics education and the existing models of competences, certifications and university curricula are in disarray.

It has been noted that human factor is the main bottleneck in developing supply chains, hindering the potential of modern technologies [4]. The lack of ontological clarity in logistics results in the viewpoints of academic authors and curricula boards ranging from narrowest views of transport arrangements, suggesting that SCM is a much higher level concept [5], to treating logistics and SCM as the same [6]. Some views suggest there is no need for logistics similarly as there is no physical distribution as a concept anymore - that SCM would offer a roof for all possible approaches. Others define distinct differences [7], and more contrasts are revealed when the concepts are modelled [8]. Such understanding appears more appropriate for education. Provided that generic SCM could not feasibly cover all niches (this paper argues that it possibly could not) and that there is a lack of other well-defined intermediary concepts (instead everyone has their own idea of differentiation), retaining and refining logistician profiles from multiple viewpoints would allow for conceptual clarity and diversity of specialists needed by the society.
It has been observed that there is a dominance of programs with business focus over technology design and engineering focus in logistics [9]. Even though typical programs of business logistics include some technology aspects, such approach is usually superficial and selective. There is of course a separate layer of curricula with more specific engineering approaches, such as warehousing systems, manufacturing logistics etc. But these are designed for narrow specialists. Under business logistics and SCM curriculum titles, the theme can be similar to traditional business curriculum and quite far from the forefront of technology. Although the idea "supply chain engineering" has been discussed in books by Dolgui and Proth [10] and Goetschalckx [11], the field has not yet developed into paradigm in its own right.

The field of higher education in logistics has been criticized in terms of gaps between academia and market relevance, such as by van Hoek [12] and Myers et al [13], as well as terminological mismatches [14]. A major metastudy of articles on logistics education was carried out by Gravier and Farris [15]. It observed 81 articles spanning over four decades on three main topics: curricula content, skills and competences, and teaching methods. However, from all articles on logistics curricula and competences, none were found to specifically treat the engineering aspect, although many included mentioning some engineering topics without specific emphasis.

A major area of debate in logistics education is the balance between theory and practice, vocational and academic training. This paper carries the viewpoint that given the complex environment of modern logistics, purely vocational training falls short without understanding conceptual issues and development, whereas the degree education has to be much aware of the changing vocational landscape. Essentially, in logistics, the two viewpoints are closer today than ever before.

One trend in terms of the future of engineering education is the growth of interdisciplinary approaches. In their vision for 2020, the National Academy of Engineering states: "the future economy will be influenced by the global marketplace for engineering services, evidenced by the outsourcing of engineering jobs, a growing need for interdisciplinary and system-based approaches and demands for new paradigms of customization" [16]. In our view, the field of logistics is facing many of these challenges and this paper contributes to meeting them, keeping in mind that engineering education is not solely a topic of higher education, but also much depends on earlier education and student perceptions $[17,18]$.

It is difficult to reach integration in the field that "exists as a fragmented discipline, housed in university departments as diverse as production management, marketing, supply management, industrial engineering and management science" [15]. It is noteworthy that: "while logistics management requires an integrated, holistic approach, its treatment in courses and textbooks tends to be either integrated and qualitative or mathematical and very specific.[19]" Both sides are of course required, but in between lies a gap, which is not sufficiently filled today by any competence standard. Therefore this paper focuses on refining "logistics engineering" and proposes a competence profile for logistics systems engineer, which the authors see as suitable approach to fill the gap so that the education in logistics could offer specialists of 
PAPER

LOGISTICS SYSTEMS ENGINEER - INTERDISCIPLINARY COMPETENCE MODEL FOR MODERN EDUCATION

interdisciplinary engineering skillset for all needs that are not met by "one-size-fits-all" SCM style programs.

It must be pointed out that differentiation of curriculum is very important to universities that are competing for best students both regionally and globally. Caution is therefore needed to ensure that standardization wouldn't go too far where it would hinder the growth of practically relevant niches and profiles. The field of logistics is, after all, rather dynamic. As it stands today, however, more focus towards standards development is needed to ensure that the engineering aspect of logistics is reinforced and that various specialization niches could be built on top of these foundations. In terms of a well-known concept in education, the ideal profile for modern logistician is indeed T-shaped.

\section{LITERATURE REVIEW}

\section{A. On the Nature of Logistics Engineering}

This section focuses on both logistics and supply chain engineering for two reasons. Firstly, logistics engineering is an area of relatively modest literature, for which the modern supply chain viewpoints help to fill the gaps. Secondly, the aspects of supply chain engineering represent the modern version and evolutionary result of logistics engineering similarly to how logistics management has evolved and transformed into SCM. It is not our intent to contrast logistics engineering to supply chain engineering. Instead, the latter keeps the former upto-date with forefront of technology and business realities.

Surprisingly little has been recently written on logistics engineering. Browsing through logistics journals resulted in findings that mostly dated to 1980 s and 1990s. This can be interpreted as a lack of broad logistics-centered focus to engineering. Of course all the practically relevant areas such as electronic data interchange (EDI), enterprise resource planning (ERP) systems, warehousing, identification and tracking technologies (AS/RS, RFID) etc. are developing both in practice (improving in functionality) and in theory, research is active and publications are abundant. In the last 15 years, logistics engineering has been exposed to intense impacts from the development of ICT, especially computer networks, mobile and wireless applications, and electronic commerce [20]. An expansive area is engineering autonomous logistics systems, such as described by [21], which reaches across all the aforementioned fields. What is mostly lacking, however, is the systematic and integrated approach to these topics as a field of engineering in its own right and as a competence profile.

There are two international organizations relating logistics to engineering: International Society of Logistics SOLE and Council of Logistics Engineering Professionals CLEP. SOLE was originally founded as Society of Logistics Engineers. Whatever reasons triggered the name change, SOLE is still focusing on uniting "individuals organized to enhance the art and science of logistics technology and education" [22]. SOLE has lead long-time extensive competence recognition programs of professional logisticians (called demonstrated master logistician and Certified Master Logistician CML). These profiles include more various engineering aspects than present in most other models of logistics competences, however, with not much conceptual backing. SOLE competence profile is later on analyzed in detail.
CLEP defines detailed understanding of the field: "Logistics Engineering is the professional engineering discipline responsible for the integration of support considerations in the design and development; test and evaluation; production and/or construction; operation; maintenance; and the ultimate disposal/recycling of systems and equipment. Additionally, this discipline defines and influences the supporting infrastructure for these systems. The practice of logistics engineering is exercised throughout the system life-cycle by trade-off studies to optimize costs and system, logistics, and performance requirements" [23]. However, last time CLEP webpage was updated was in 2012, which points out the body is no longer actively functioning.

There are few books specifically on logistics engineering and therefore it is unfortunate that the most prominent of them, combining chapters from over 40 authors, does not properly define the area [24]. Furthermore, Joel Sutherland from Lehigh University has pointed out a controversial understanding that there are only selected few differences between business and engineering logistics, which can be summarized with logistics engineers being more focused on quantitative approaches [25]. It is relevant to note that this view much differs from approach suggested in this paper. The problem in such use of terminology, is that it does disservice to both logistics engineering and supply chain management fields, as the engineering element tends to suffer in logistics and supply chain education without explicit and broad conceptual focus.

Perhaps a more appropriate approach would be to treat logistics as a sum of "managing current logistics environments" and "designing and (re)engineering new logistics systems and subsystems". In such construct, the former is business management view (i.e. SCM) and the latter would be the view of engineering, which would incorporate and facilitate thorough approaches to processes, networks and systems design. That being said, it must be acknowledged it is misleading to overly contrast logistics engineering to business as both serve to improve processes, organizational performance and contribute to competitive advantages of supply chains.

Recently, the term logistics engineering has seen attention in the military. The American consultancy Booz Allen Hamilton has issued a report on logistics engineering as a foundation to ensure availability, lifecycle management and cost optimization. The core idea can be directly translated to business context: "Logistics engineering brings science to the art of logistics and optimizes difficult programmatic decisions in a recourseconstrained environment. /.../ Logistics engineering is a technical discipline that applies analytics and tools to facilitate knowledge-based decision-making through-out a system's life-cycle. Logistics engineering addresses all facets of systems acquisition" [26]. It is also noteworthy to point out that in their view, logistics engineering does not refer only to technology design and life-cycle analysis, but also process engineering, incorporating approaches such as lean six sigma and theory of constraints.

As for what details logistics engineering should entail in the military, D. Sanford has reflected on a study carried out across 101 air force logistics-related officers, which emphasized five key areas of competences: material management, distribution, air transport, fuels and contingency operations. The study pointed out that the 
current training of logisticians is too vague, which ends up with personnel "jack-of-all-trades, expert at none" [27].

To strengthen engineering side of logistics, supply chain engineering is an emerging concept with good potential. One recognized supporter of this concept is $\mathrm{M}$. Goetschalckx from Georgia Institute of Technology, an author of the book with the same name, which preface notes: "A supply chain system can be loosely described as a system that - through procurement, production, and distribution - delivers goods to satisfy the demands of customers. As a consequence, there exists a very large variety of supply chain system types with different goals, constraints, and decisions. But a systematic approach to the design and planning of any supply chain can be based on the principles and methods of system engineering. [11]" The book promotes various process modelling viewpoints and practical solutions algorithms ranging across engineering design, forecasting, transport routing and scheduling, inventory optimization, supply chain systems and models.

J. Miebach is considered to be one of the first authors using the term supply chain engineering. The core of such view is similar - an optimal supply chain can perform according to objectives and deliver success if its structure is holistically designed merging technical and economical viewpoints [28]. To end this section, we'd like to emphasize that engineering treatments in logistics are not only about technological innovations but also process innovations, relating to the concepts of systems engineering [29], concurrent engineering and business process engineering [30]. This means that an interdisciplinary engineering view of logistics reaches into process and project management.

\section{B. On the Nature of Systems Engineering}

$\mathrm{SE}$ is a more established field compared to logistics engineering. Even though multiple definitions for SE exist and the field itself is dynamic and evolving, for our purposes a simple formulation - a field responsible of designing, enabling and managing complex engineering systems over their life cycle - is a suitable starting point.

The lifecycle is explained in a V-shaped model, which presents seven main components of systems engineering (which may happen concurrently and iteratively): concept development, requirements engineering, system architecture, design, development, integration, testing, evaluation, operation and maintenance [31]. The underlying idea of SE is to be customer-oriented so that required functionality of the system drives the entire engineering process [32] A more specific concept, enterprise engineering, aims for a comprehensive view of engineering activities at the customer enterprise [31].

A systems engineer serves to translate customer needs into specifications that can be realized by system development. In order to realize successful systems, systems engineer supports a set of life cycle processes beginning early in conceptual design and continuing throughout the life cycle. The systems engineer must analyze, specify, design, and verify the system to ensure that functional, interface, performance, and other quality characteristics, and cost are balanced to meet the needs of the system stakeholders [33].

There are various models of competencies in the field of SE, comparatively analyzed by Ferris [34]. Competence in this context is meant in a broad sense reaching across skills, knowledge, abilities, behaviors and other characteristics that need to be performed in work roles and that are observable and measurable. The models with wider recognition that were reviewed for our study are:

a) "INCOSE Systems Engineer Competency Model" by International Council of Systems Engineering, first developed in 2005 [35]

b) "MITRE Systems Engineering Competency Model" by MITRE Corporation from 2007 [36]

c) "NASAs Systems Engineering competencies" by Academy of Program/Project and Engineering Leadership APPEL [37]

The INCOSE framework is divided into three theme areas - systems thinking, holistic life cycle view and systems management - and further expanding into 20 specific areas. It has been noted that "the INCOSE framework is simple and easy to understand and focuses on specific aspects of competency rather than trying to be a master of all disciplines" [38].

The MITRE model consists of 36 competencies organized into five sections: enterprise perspectives, systems engineering life cycle, systems engineering management, engineering technical specialties and collaboration and individual characteristics. The model then expands into over 100 items of tasks or behaviors, which are described on three levels: foundational, intermediate and expert, noting that a systems engineer is likely to be expert only in some competencies, intermediate in others, and foundational in others [36].

The APPEL model consists of ten competency areas. In contrast to previously described, the model explicitly includes areas of project management, human capital management and knowledge management. All areas expand into 37 competencies, which further consist of 114 elements. The model is aimed primarily for use in NASA, as one of the ten areas is "NASA internal and external environments" [37]. However, the entire scope of the model is, one could say, even more comprehensive compared to aforementioned ones.

The field of engineering education has not been without criticism. Patil and Codner note: "There is increasing evidence of a mismatch between graduate student's skills developed during their studies and those needed by gradate engineers in the workplace" [39]. Davidz and Nightingale have pointed out "the adequacy of certification programs remains controversial, primarily due to their newness for widespread certification" [40].

Recently, developing the competence in systems engineering in the profile of any engineer has been advocated by field C. Wasson. Wasson focuses on filling the void in general engineering education to include a course dedicated to SE fundamentals, which in this view is a minimum set of topics required from every engineer: “... understand the difference in SE as a professional career discipline versus a domain engineers such as electrical, mechanical, etc. that apply SE methods, processes and tools to solve domain specific problems. Both contextual roles are crucial to meeting the interdisciplinary team needs to develop complex systems" [41]. All in all, Wasson lists 43 elements of SE topics that should be included in any domain engineer profile. 


\section{Methodology - THE RoAd TO New Model}

This paper aims at synthesizing an integrated and interdisciplinary model of competence areas in logistics as seen from the viewpoint of systems engineering. The first empirical research task was to evaluate and demonstrate the extent to which modern logistician competence models treat the topics of SE. It is not expected that any model positioned centrally across the wide spectrum of logistics would cover the entire scope of SE, as one is a fieldspecific concept, the other is not.

Still the two fields share common characteristics such as hugely varying application environments, the need for inter-disciplinary approach, and rapid development of technologies and business environment dynamics, which pushes solutions towards concurrent engineering. Therefore linkages on various viewpoints could be assumed. Logistics is an area of domain engineering, which ought to include the systems viewpoints to facilitate proper development of interdisciplinary skillsets. After all, logistics in service of company goals and strategies is nothing but a large-scale complex system itself. This implies that the underlying engineering element in logistics is strong enough so that integrating system engineering view wouldn't be something that would meet opposition in principle.

As the field of logistics is relatively little standardized, there are many competing certifications and competence profiles, a selection of which is covered here. The selection was influenced by including viewpoints of European and American origin describing the broad reach of logistics. On the question of the level of education, the focus is on university-level, though it is nigh impossible to draw the line between undergraduate and graduate levels in competence standards. The models usually solve this by flexibly defining various proficiency levels, as understandably a working model must retain some adaptability. Our analyzed selection consists of:

a) Designated logistician profile by SOLE [42],

b) Logistics professional by European Logistics Association (ELA) [43]

c) International Diploma in Logistics by Chartered Institute of Logistics and Transport (CILT) [44]

d) Distribution and logistics managers' competency model by The Association for Operations Management (APICS) [45]

On the question of which model of systems engineering competence to utilize as initial basis for comparison, we selected the model by MITRE, taking into account that:

1) the model appeared to have the best balance across a variety of factors;

2) it is much detailed;

3) it had the best structure of the models reviewed, which considerably simplified the analysis.

The methodological approach is visualized on Fig. 1.

The results of initial comparative analysis are summarized in Table I. We note that comparing two competence models is not overly precise process and it is difficult to quantify the outcome, but general evaluations can still be made. For visual clarity, a blank square means that no aspect of given competence was identified in the

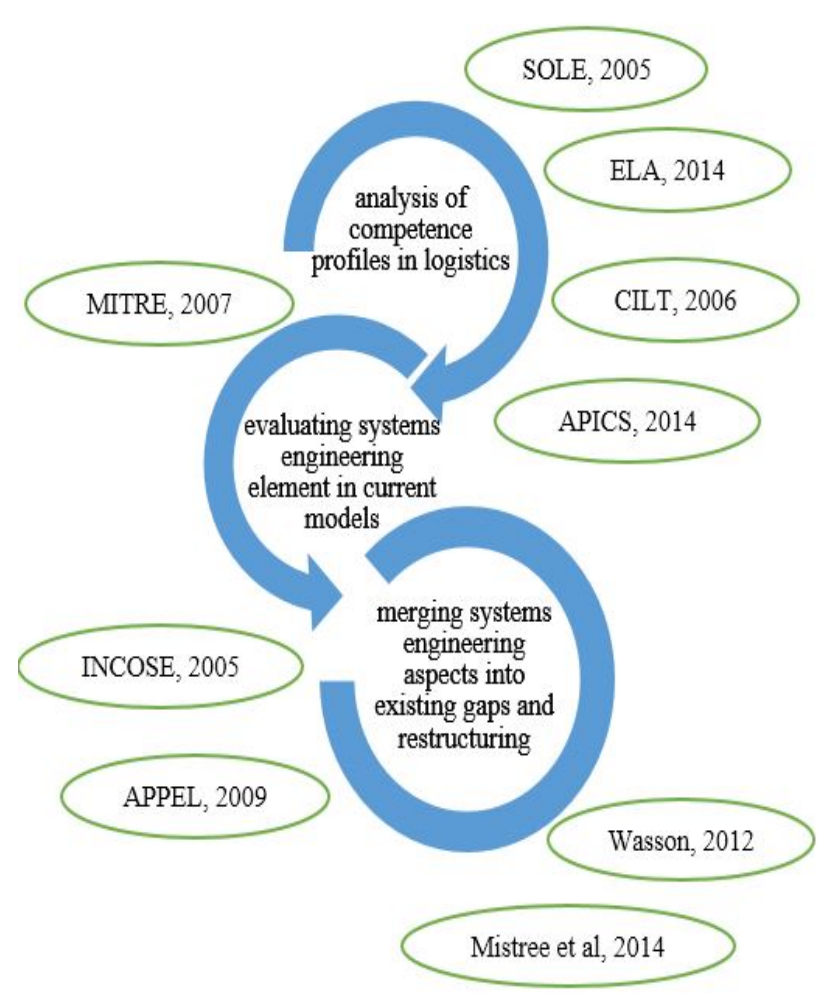

Figure 1. Applied methodology and main inputs in new model design.

Source: authors' compilation

model and the stronger the filling, the closer linkage was perceived.

As Table I demonstrates, there are notable differences across models in including the elements of SE. Some aspects are more strongly present due to nature of the field, such as quality and risk management aspects. Others are only occasionally mentioned here and there. For example, one might assume that human factor is relevant in designing warehouse workflow and processes, and of course it is, only that the models have not seen it important enough to explicitly point out. All in all, this demonstrates how various models in logistics competencies differ and send mixed signals to universities and to society.

Comments have to be made about SOLE model. Whereas the typical way of a competence model or a certification program is to set obligatory and clearly defined limited optional components, then the approach applied by SOLE presents lengthy list of "suggested study areas" in terms of "functional training" and "enabler training", which means that the model is able to cover wider scope but in itself it does not guarantee that a certified specialist would know all or even most of the areas. Taking that into account it is still somewhat noteworthy that the model built originally with engineering focus in mind does not reference many aspects of $\mathrm{SE}$, at least not according to comparing the formulations with MITRE components. It is therefore important to note that while SOLE model does treat various SE topics right next to more conventional logistics topics, the areas are only represented as keywords so one really can't treat SOLE as a competence model but just a compiled list of topics relating to logistics. 
TABLE I. PRESENCE OF SYSTEMS ENGINEERING ASPECTS IN LOGISTICS COMPETENCE MODELS AND CERTIFICATION PROGRAMMES

\begin{tabular}{|c|c|c|c|c|}
\hline \multirow[t]{2}{*}{ MITRE competency fields } & \multicolumn{4}{|c|}{ Presence in logistics models } \\
\hline & SOLE & $E L A$ & CILT & APICS \\
\hline \multicolumn{5}{|l|}{ 1. Enterprise Perspectives } \\
\hline $\begin{array}{l}1.1 \text { Comprehensive viewpoints to } \\
\text { system context and modeling }\end{array}$ & & $\because$. & $\therefore \cdot$ & $\because \cdot \square$ \\
\hline 1.2 Innovative approaches & $\because \because$ & & $\because$ & \begin{tabular}{|c|}
$\cdot .2$ \\
\end{tabular} \\
\hline $\begin{array}{l}\text { 1.3 Foster stakeholder } \\
\text { relationships }\end{array}$ & 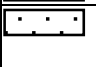 & 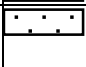 & 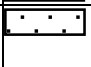 & 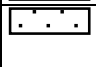 \\
\hline \multicolumn{5}{|l|}{ 2. Systems Engineering Life Cycle } \\
\hline 2.1 Concept definition & $\therefore \cdot$ & & $\therefore$. & $\begin{array}{ll}\cdot \cdot \cdot \\
\end{array}$ \\
\hline 2.2 Requirements engineering & $\because \because 9$ & & $\therefore$. & \begin{tabular}{|l|l|}
$\cdot .2 \cdot$ \\
\end{tabular} \\
\hline 2.3 Architecture & 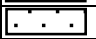 & & $\therefore$ & \\
\hline $\begin{array}{l}\text { 2.4 Systems design and } \\
\text { development }\end{array}$ & \begin{tabular}{|c|}
$\cdot \cdot \cdot$ \\
\end{tabular} & & $\cdot$ & $\because \because$ \\
\hline 2.5 Systems integration & $\because \because$ &. &. & 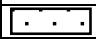 \\
\hline 2.6 Test and evaluation & \begin{tabular}{|c|}
$\cdot \cdot \cdot \cdot$ \\
\end{tabular} & ב. &. & \begin{tabular}{|l|l|}
$\cdot \cdot \cdot \cdot$ \\
\end{tabular} \\
\hline $\begin{array}{l}2.7 \text { Implementation and } \\
\text { maintenance }\end{array}$ & & & \begin{tabular}{|lll} 
& & \\
& $\cdot$ & $\cdot$ \\
\end{tabular} & $\begin{array}{r}\cdot \cdot \cdot \cdot \\
\end{array}$ \\
\hline \multicolumn{5}{|c|}{ 3. Systems Engineering Planning and Management } \\
\hline 3.1 Transformational planning & $\therefore \therefore$ & $5 \cdot 2$ & $\because$ & $\begin{aligned} \cdot \cdot \cdot \\
\end{aligned}$ \\
\hline 3.2 Acquisition support & 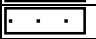 & $\therefore$ & .9 & 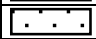 \\
\hline 3.3 Contractor evaluation & $\because$ & $\because \div$ & $\because \div$ & $\square .9$ \\
\hline 3.4 Risk mana & 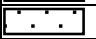 & $\therefore$ & 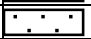 & $\therefore .9$ \\
\hline 3.5 Configuration management & i.ं. & & & $\therefore 9$ \\
\hline 3.6 Integrated logistics support & $\begin{aligned} \cdot \cdot \cdot \\
\end{aligned}$ & 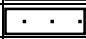 & 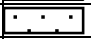 & $\therefore 9$ \\
\hline $\begin{array}{l}\text { 3.7 Quality assurance and } \\
\text { measurement }\end{array}$ & & & 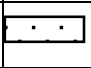 & $\begin{array}{llll}\cdot & \cdot & \cdot \\
\end{array}$ \\
\hline $\begin{array}{l}3.8 \text { Continuous process } \\
\text { improvement }\end{array}$ & & & & $\cdot \cdot \cdot$ \\
\hline \multicolumn{5}{|c|}{ 4. System Engineer Technical Specialties } \\
\hline 4.1 Cost/benefit analysis & 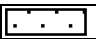 & & $\because$ & $\because \because 9$ \\
\hline 4.2 Human centered engineering & $\because \div$ & & & \\
\hline 4.3 Modeling and simulation & 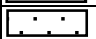 & & 8. & $\because \div$ \\
\hline 4.4 Security engineering & 5 & & & 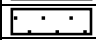 \\
\hline $\begin{array}{l}4.5 \text { Reliability, maintainability } \\
\text { and availability }\end{array}$ & $\because \dot{\theta}$ & & $\because$ & $\because \cdot$ \\
\hline 4.6 Safety engineering & ${ }^{\circ}$ & & & \\
\hline $\begin{array}{l}\text { 4.7 Software and information } \\
\text { engineering }\end{array}$ & & & & \\
\hline $\begin{array}{l}4.8 \text { Communications and network } \\
\text { engineering }\end{array}$ & & & $\because$ & $\cdot$ \\
\hline $\begin{array}{l}4.9 \text { Collaborating with technical } \\
\text { specialties }\end{array}$ & & \begin{tabular}{|c|}
$\cdot \cdot \cdot$ \\
\end{tabular} & $\dot{*}$ & 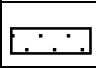 \\
\hline \multicolumn{5}{|c|}{ 5. Collaboration and individual characteristics } \\
\hline 5.1 Building trust & & $\therefore .9$ & & $\because \because 9$ \\
\hline 5.2 Building a successful team & Eं'ं & 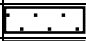 & $\because \div$ & $\because \because 9$ \\
\hline 5.3 Communicating with impact & 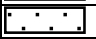 & 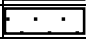 & 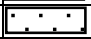 & $\because \because$ \\
\hline 5.4 Persuasiveness and influence & & $\because 2$ & $\because \because$ & 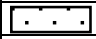 \\
\hline $\begin{array}{l}5.5 \text { Facilitating and managing } \\
\text { change }\end{array}$ & & $\therefore$ & 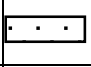 & 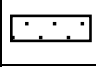 \\
\hline 5.6 High quality standards & 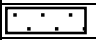 & & \begin{tabular}{|r|r|}
$\cdot \cdot \cdot \cdot$ \\
\end{tabular} & 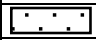 \\
\hline 5.7 Result orientation & & $\dot{E \cdot} \cdot \dot{2}$ & $\begin{array}{r}\cdot \cdot \\
\end{array}$ & \begin{tabular}{|l|l|}
$\cdot \cdot \cdot 3$ \\
\end{tabular} \\
\hline 5.8 Adaptability & 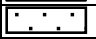 & $2 \therefore$ & & \\
\hline 5.9 Integrity & & & & \begin{tabular}{|l|l|}
$\cdot \cdot 2$ \\
\end{tabular} \\
\hline
\end{tabular}

a. Darker shade of grey represents more direct relationship

The three other models are more traditional competence models by their structure and formulations, but, alas, they don't dedicate too much attention to SE specifically. Perhaps such outcome could have also been assumed beforehand. The result in Table I confirms the expectation that SE component in logistics competence models can be, at best, labelled "could be improved".

Such result could reasonably be interpreted as a gap which should be overcome. Such integration between systems engineering and logistics wouldn't in our view be just a curiosity, but would reinforce engineering element in logistics, which, if applied in practice, would help universities to present students with a stronger interdisciplinary skill profile. Currently, although mostly everyone in the field would agree that interdisciplinary approach is a requirement in logistics, the profiles actually developed in many universities are not that interdisciplinary as they could be, if there also would be a standards pushing for such change.

Therefore we set out to formulate our view of what should logistics system engineer's competence profile consist of. The process of model creation required at first to differentiate various competence areas, which was not overly difficult. The more challenging part was going through the existing logistician models once more to make sure that our approach would not leave any essential viewpoints aside. The task was complex as all models have their own inner structure.

The next step was to define the extent to which systems engineering topics would fit into the new model. As the primary goal of our model is to use it as a tool for curriculum design, the extent of systems engineering topics from INCOSE, MITRE and APPEL models was consolidated and shortened, taking into account approach suggested by Wasson about the content of minimal systems engineering module for domain engineering fields [41]. In the vision of our model, systems engineering material would need to cover around $20 \%$ of curriculum, keeping the profile still field-specific with additional strong systematic foundation.

Additional effort was made to map required individual foundational competencies right next to field-specific task competencies. There is, of course, an abundance of personal traits and attitudes that are foundational for a field covering such a variety of jobs as logistics. As Table I showed, the models include some and leave out others, so we attempted to consolidate the most essential across all the models. Additionally, just this year, a group of authors published their approach to foundational aspects expected from any engineer [46], so we made sure to integrate their approach as a double check for quality.

\section{Result - A COMPETENCE PROFILE FOR Logistics SYSTEM ENGINEERS}

First of all, the structure of our proposed model is shown on Fig. 2. It consists of six layers, starting from foundational engineering competences. In the presented view, systems engineering treatments form the conceptual foundation to the model, so that all the layers are built upon it. On top of that lies the layer of specific technologies that need to be engineered and maintained in logistics, followed by a core layer of more conventional logistics topic areas. It is difficult to offer non-overlapping categorization to logistics technologies. In current perspective, three technology areas are parts of material flow whereas the last component suggests the dimension of automation and intelligent technologies is applicable about almost all aspects of modern logistics technologies.

The core includes all operational and tactical elements of logistics and supply chain related decisions. At the very center lies a lost list of issues grouped as "logistics and supply chain network design and configurations", which in this context foremost includes the areas of supply chain design, supplier selection and evaluation, physical material flow characteristics configuration, transport and material handling arrangements and optimization. 
PAPER

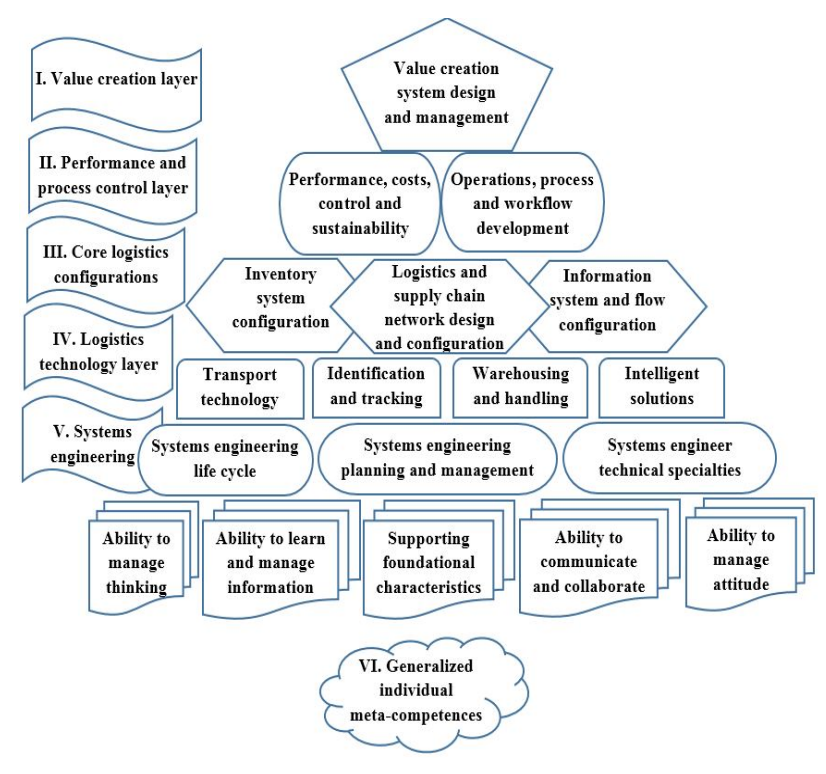

Figure 2. The building blocks of logistics systems engineer's profile

Source: authors' compilation

The core is supported by two pillars, which represent two main variables in logistics networks: inventory and information. Changes made in these configurations require careful management and understanding the trade-offs across entire logistics system.

Information systems and information flow configurations belong into the "core" rather than form just one technology pillar because information is the "glue", which keeps all the systems running and facilitates both planning and control across variety of dimensions. All technology implementation areas include information flow aspects one way or another anyway, so there is no distinct line, but then, everything is related to everything else in the picture of logistics systems. Information technology section is intentionally separated from physical technologies to demonstrate the importance and applicability in almost any logistics environment, whereas other technologies are much more context related.

The goal of presenting these three aspects together points out that the core reaches across the initial requirements for logistics system (understanding customer demand) to arranging the optimal supply network (suppliers, cost and time implications of deliveries, inventory costs and risks) and keeping the system flexible by optimal management of information and inventories. This layer also involves network optimization.

The following layer adds the view of operations and processes and stresses that improvements to logistics system do not only come from technologies, network configuration and better information management but also from optimized workflow and processes - or indeed, that proper optimization of all types of processes is what facilitates the more hands-on improvements in logistics quality and stakeholder satisfaction. This layer also includes all forms of performance measurement in both financial and non-financial aspects in order to provide direct input to all other areas and drive continuous improvement.
The top of the model, "value creation system design and management" is the strategic capstone of entire logistics system that must explain the driving force why everything is running in the first place. The simple reason is the customer. The more general reason lies in the outputs that the system is designed to generate that are valued by the stakeholders. This aspect is on top because of importance but also that it is mostly the only aspect what is directly perceived of the system from the outside.

Understanding the value creation system gives meaning to all activities in scope of logistics. Principle changes on this level need to trickle down across the layers to accommodate accordingly: to streamline processes, create new and reconfigure existing supply networks, identify system current and future priorities, define investments and bring about innovation. However, to make it happen, the roots, i.e. the foundational competences, must all serve as enablers. Also, sometimes systems develop and evolve from bottom to top and the more dynamic the environment, the more crucial is to take advantage of the emerging options.

Initially, the capstone was titled just "value system", which would be sufficient, if it would not already have been used in the context of ethical and cultural values in stakeholder theory. Therefore, the aim here was to avoid confusion. In this paper, value is in principle the sum of utility that a system provides for the stakeholders.

The competence model in its full form is rather extensive. The entirety of topics treated under various programs of logistics is still notably wider [47], so the model presented here implies dedicated differentiation. Though, even if limited to competence elements at the level of listing required learning outputs, the model is longer than the constraints presented by this paper. Therefore on most competence layers in the following tables II and III, only an abbreviated form of competences is presented. This consolidated the size of tables to around $60 \%$ of its original form. The authors are glad to distribute the complete version to anyone interested on contact. The meta-competences referenced in table III are integrated mostly in their original form according to Mistree et al [46].

Due to extensive reach of the created competence profile, it is not realistic that such training would be achieved in the typical three years of undergraduate studies. The authors are therefore on a position that the programs for logistics systems engineers would have to be full five year study programs similar in length to other fields of engineering.

One difficulty in implementing such profile in universities would be cost. The field of logistics covers an abundance of technologies, which requires universities to invest into a variety of simulation, testing and other lab equipment. Another requirement is tight cooperation with industry to ensure the problems research by students would be as realistic as possible and that quality internships would be facilitated. In summary, this is a complex problem for universities with lesser resources and this is, in authors' view, one of the reasons why pure business-focused logistics programs are so abundant they are substantially cheaper and easier to manage. 
TABLE II. SELECTED COMPETENCIES IN THE PROFILE OF “LOGISTICS SYSTEMS ENGINEER”, LAYERS I-III

\section{A. Value creation system design and management (shortened)}

A.1 Views the organization as a system that converts inputs to outputs A.2 Understands the role of management activities and different organisation structures and applies fundamental management theories and concepts in practice

A.3 Participates in strategic planning, including long-term strategic goals, and relates strategic priorities to market and business environment trends, current status of the company and to goals of functional strategies and tactical plans

A.4 Analyses market and customer requirements and expectations, needs and desires, order qualifying and order winning factors and how the value generated by company is perceived in the mind of customer as a primary input to defining value system priorities

A.5 Analyses short- and long-term trends in the industry, region and micro-, macro- and global environment

A.6 Applies various analytical techniques to evaluate and improve company and main products position on the competitive landscape

A.7 Defines the system and component processes of value generation and the role of supporting activities in a company

A.8 Defines value offer to customers, applies differentiation and positioning concepts based on marketing data and assists in outlining marketing strategies as means to communicate the value offer to target customer segments

A.9 Analyses comparatively competitive forces and pressure on market A.10 Defines goals and principles of the value systems, key success factors and product and service standards in value systems

A.11 Performs value stream mapping and outlines value system improvement plan accordingly

A.12 Understands the role of suppliers, customers and business partners in the supply chain, how it influences the total value perceived by end customer and how to coordinate actions, priorities and management principles to increase total value generation

B. Performance, costs, control and sustainability (shortened)

B.1 Evaluates general financial performance of an organization, the performance and the success or failure rate of projects, products and services and their value systems, understands and calculates financial performance indicators and related concepts and understands how changes in logistics system can affect financial performance

B.2 Defines strategic and tactical key performance indicators for the company and defines measurement systems of performance indicators B.3 Develops strategic objectives of logistics and value system relating to SCOR model metrics: reliability, responsiveness, adaptability, costs and asset utilisation

B.4 Defines quality standards and plans and analyses quality inspection and improvement

B.5 Defines, plans, analyses and controls financial and project management aspects of development projects and investments

B.6 Employs the technique of break-even analysis and determines optimal operating level

B.7 Calculates project and company cash flow forecasts, present value investment comparisons and risk-adjusted return calculations

B.8 Understands basic principles of sustainability and evaluates internal sustainability of the logistics systems

C. Operations, process and workflow development (shortened)

C.1 Assists in developing a culture and organizational behaviour where departmental sub-optimisation is minimised and cooperation is supported and understood as a central value that would encourage visibility of company performance and understanding "the big picture" C.2 Understands the trade-offs between system priorities and coordinates processes accordingly

C.3 Supports the culture where changes in priorities, processes and workflow are accepted and communicated to keep the workforce agile and the products and processes adaptable

C.4 Understands that every part of main process in a company needs to create value and develops processes accordingly

C.5 Identifies and eliminates causes of quality problems, analyses and reduces process variation and strives to remove non-value-adding components in processes and workflow

C.6 Analyses and improves procedural standards, structures, responsibilities, job and task descriptions and coordination and control mechanisms

C.7 Applies systematic approach to increasing system performance through streamlining, coordination and cycle time reduction
D. Logistics network design and configuration (shortened) D.1 Forecasts demand for products and services with various methods and techniques

D.2 Synchronizes supply with demand by determining the need for material and operational capacity to address expected demand and executing the resulting plans

D.3 Designs supply chain network and logistical flow in alignment with general priorities of the value systems

D.4 Defines specific customer service standards and develops objectives and indicators across the supply network in terms of quality, cost, flexibility, adaptability, responsiveness, productivity, efficiency and customer satisfaction

D.5 Analyses and optimizes the location of physical supplies chain facilities (warehouses, hubs, factories, stores), taking into account the effects on lead times, availability, inventory and transport related costs, risks and other supply chain performance areas

D.6 Carries out lead time and order cycle time analysis and identifies potential improvements

D.7 Optimizes material and information flow between supply chain participants and improves process control

D.8 Analyses the applicability and implements various supply chain management concepts such as just-in-time, QR, CPFR, VMI, etc.

D.9 Coordinates manufacturing and logistics flows and planning systems

D.10 Understands, analyses and optimizes the total supply network capability by controlling processes, identifying and removing bottlenecks, managing trade-offs and coordinating decisions across functional areas

D.11 Applies various operations management techniques in controlling and optimizing logistics activities

D.12 Analyses the applicability of technologies in the field of logistics and process control to improve performance

D.13 Appreciates the impact of supply chain operations to environment and applies principles such as renewable raw materials, reverse logistics, recycling, paperless operations and green transport

D.14 Analyses the feasibility and impacts of various supply chain configurations (MTS, ATO, MTO) and optimizes current configuration D.15 Carries out make-or-buy analysis, negotiates contracts with suppliers and service providers

E. Inventory system configuration (shortened)

E.1 Defines inventory management strategies and objectives and balances demand with supply

E.2 Calculates and develops actions to improve key inventory performance metrics

E.3 Converts demand information and forecasts into operations and purchasing schedules

E.4 Defines, implements and develops inventory control procedures

E.5 Analyses and categorizes inventory with various techniques and defines dedicated inventory management principles to categories

E.6 Determines optimal ordering systems, order quantity, safety stock and availability control parameters

E.7 Understands and calculates inventory holding and ordering costs

E.8 Understands and counters the bullwhip effect

E.9 Understands the trade-offs in inventory management between availability, costs, risks and control

E.10 Analyses the availability of products and ways to increase it

E.11 Optimizes inventory levels and holding costs while simultaneously improving availability

F. Information system and flow configuration (shortened)

F.1 Understands fundamentals and defines role of MRP/ERP software

F.2 Applies EDI and other modern solutions in B2B communication and analyses the impact on logistics performance

F.3 Designs e-commerce solutions and evaluates impact on customers F.4 Compiles and models the user requirements of information systems F.5 Integrates activities across organizations on the supply chain by ensuring information visibility

F.6 Analyses the relations how IT systems affect processes and vice versa

F.7 Accounts for security and privacy issues in IS design

F.8 Defines and implements data mining and various analytic systems

F.9 Manages IT system transition and integration processes

F.10 Facilitates visibility by designing suitable tracking systems

F.11 Considers various viewpoints and trade-offs in information system analysis, including reliability, features, security, capacity, flexibility, workplace ergonomics etc 
TABLE III. FOUNDATIONAL COMPETENCE LAYERS IN THE PROFILE

\section{G. Logistics technology layer (shortened)}

G.1 Understands modern technologies and future trends in the areas of transport, tracking, warehousing, handling, and autonomous solutions in terms of capabilities, costs, requirements, constraints and risks G.2 Analyses current and future need for logistics technology innovation and the impact of solutions to supply chain performance G.3 Initiates and carries out feasibility and impact studies of technology innovation projects in logistics

G.4 Matches value system needs with technological capabilities

G.5 Cooperates and consults with experts in the field

G.6 Manages new logistics technology implementation projects throughout the life cycle

G.7 Carries out thorough risk analysis of implementation projects, including aspects of safety and security

G.8 Defines human, information system and technology interfaces and integrates physical technologies with IS and workflow

G.9 Applies human-centered engineering in design and implementation

G.10 Cooperates with external experts to create systems reaching across organizational boundaries

G.11 Specifically, is knowledgeable about current state, trends and applications of alternative fuels, vehicle designs, self-driving vehicles, cargo room characteristics, alternative energy sources, warehousing and racking solution, AS/RS, automatic handling and packaging, sensors and automatic identification, monitoring and inspection and information system designs and concepts

G.12 Is aware of the current and future boundary between human and machine-based operations and understands the required conditions when human labour can be replaced with machines

G.13 Envisions potentially applicable solutions in organization in the near future, relating to technological trends and evolving industry practices

G.14 Understands the synergetic relations between material flow technologies, information system and information flow configurations and utilises it in systems development

G.15 Analysis the level and extent of technology- and innovationrelated competencies in organization and assists in forming training plans as well as employment plans

\section{H. Systems engineering layer (shortened)}

H.1 Understands SE terminology, foundational process and planning, design and control concepts

H.2 Defines system strategies, mission statements and specifications

H.3 Researches, assesses and manages system stakeholder requirements

H.4 Analyses system complexity and decomposition

H.5 Understands and formulates system element architecture

H.6 Defines system interfaces and manages phases, modes and states

H.7 Performs analysis of alternatives

H.8 Understands the system life cycle analysis, dynamics and planning and implementing of various functions through-out the life cycle

H.9 Plans and analyses reliability, availability, and maintainability

H.10 Applies tools and methods of system performance measurement, modeling and optimization

H.11 Estimates system life-cycle costs

H.12 Analyses and manages safety aspects

H.13 Is able to perform configuration and data management, technical reviews and audits

H.14 Identifies, assesses and mitigates risks

H.15 Is proficient in fundamental tools of project management

\section{Generalized individual meta-competences}

I.1 Ability to learn and manage information

I.2 Ability to manage thinking

I.3 Ability to communicate and collaborate

I.4 Ability to manage attitude

M.1 Accountability

M. Supporting foundational characteristics

M.2 Adaptability

M.3 Creativity

M.4 Empathy

M.5 Integrity

\section{CONCLUSIONS}

This paper synthesized the competences of systems engineering with modern logistics engineering, creating a profile "logistics systems engineering", which fills a gap in logistics education by reinforcing the engineering aspect and aims to counter the present bias in logistics education towards traditional business management.

In the process of model creation, the two prominent questions were of conceptual reach: to what extent should SE aspect be included and what should be the proper balance between engineering and management aspects in the resulting model. The applied approach aimed for wider coverage of topics so that engineering focus would be covered by both foundational systems engineering concepts as well as domain-specific technologies and they would all still be related with wider organizational and business network context that the authors called "value creation system". In a sense, the resulting model is even more interdisciplinary than many existing treatments of professional logistician profiles and that was intentional. The competences for logistics systems engineer integrate the aspects of systems, networks, physical technologies, ICT, product and process engineering.

The primary theoretical contribution of this paper is to offer a means for academia to treat logistics topics differently from the dominating SCM concept, which does not dedicate enough systematic attention towards engineering aspects (although a smaller set of universities do, regardless). In terms of the name for such concept, both logistics and supply chain engineering are almost suitable. The latter is more common in literature, while the former would offer a new face for logistics along with sustainable longevity. Regardless of which name prevails, the authors expect that the content of the suggested profile will stand the test of time and be applied by universities.

It must be acknowledged that the result, as any competence model, is never "final" but open to interpretations and accommodations in any specific curriculum case and changes on educational landscape. Still, the result appears complete enough to be used as curriculum development input in the case of authors' own alma mater. The profile is directed at integrated bachelorand master-level studies. Further, the profile could be implemented as occupational standard and a certification system. The areas of directly related future research would be case studies of implementing such programs, studies aimed at identifying the view of industry stakeholders towards the concept and developing optimal teaching methods that would merge systems and domain-specific views in the context of modern ways of learning.

There is another term suitable for the field - intelligent logistics. The concept is barrowed from intelligent transport systems and extended across the cross-functional nature of logistics. We are living in an age where there is less and less physical human labour in logistics and more automation and autonomous systems in in-house operations. Furthermore, we may see autonomous solutions in logistics on the streets in a future that is not too far away that educators wouldn't need to think about it today. All the current and projected developments require people with proper educational profiles and this forms the frontier of modern logistics engineering. 


\section{REFERENCES}

[1] P.F. Drucker, “The Economy's Dark Continent," Fortune, April 1962, pp.265-270.

[2] M. Porter, "Competitive Advantage," Free Press, New York, 1985.

[3] T. Niine, O. Koppel, "Logistics management in the era of supply chain management - A gap in academic literature," Journal of Business Management and Applied Economics, 2014, vol. 3, is. 3, pp. 1-23.

[4] D. Kisperska-Moron, "Evolution of competencies of logistics and supply chain managers," Logforum: Electronic Scientific Journal, 2006, vol. 6, is. 3, no. 3. URL: http://www.logforum.net/

[5] C. Haksever, B. Render, "Service Management. An Integrated Approach to Supply Chain Management," FT Press, 2013, 508 p.

[6] P. D. Larson and A. Halldorsson, "Logistics versus supply chain management: an international survey," Int. J. Logistics Research and Applications, vol. 7, is. 1, pp. 17-31, 2004.

[7] P. Schönsleben, Integral Logistics Management, Auerbach Publications, 2007.

[8] A. Rushton, P. Croucher, and P. Baker, Handbook of Logistics and Distribution Management, $4^{\text {th }}$ edition, Kogan Page, 2010, 665 p.

[9] Y.-C. J. Wu, „Contemporary logistics education: an international perspective," Int. J. Physical Distribution \& Logistics Management, vol. 37 no. 7, pp. 504-528, 2007.

[10] A. Dolgui and J.-M. Proth, Supply Chain Engineering. Useful Methods and Techniques, London: Springer-Verlag, 2010.

[11] M. Goetschalckx, Supply Chain Engineering, Springer, 2011.

[12] R. I. van Hoek, "Logistics education: achieving market and research driven skill development," Int. J. Physical Distribution \& Logistics Management, vol. 31 no. 7/8, pp. 505-519, 2001.

[13] M. B. Myers, D. A. Griffith, P. J. Daugherty, and R. F. Lusch, "Maximizing the human capital equation in logistics: education, experience, and skills," J. Business Logistics, vol. 25, no. 1, pp. 211-232, 2004.

[14] B. Gammelgaard and P.D. Larson, "Logistics skills and competencies for supply chain management," J. Business Logistics, vol. 22, is. 2, pp. 27-50, 2001.

[15] M. Gravier and M. Harris, "An analysis of logistics pedagogical literature. Past and future trends in curriculum, content and pedagogy," Int. J. Logistics Management, vol. 19 no. 2, pp. 233253, 2008.

[16] Educating the Engineer of 2020: Adapting engineering education to the new century, Washington: National Academies Press, 2005.

[17] Educating tomorrow's engineers: the impact of government reforms on 14-19 education, London: House of Commons Science and Technology Committee, 2013.

[18] A. Depieri and R. Deus Lopes, "Student's skills perceptions for engineering," 2014 IEEE Global Engineering Education Conference (EDUCON), pp. 402-407, Istanbul, Turkey, 3-5 April 2014.

[19] G. Ghiani, G. Laporte, and R. Musmanno, Introduction to Logistics Systems Management, $2^{\text {nd }}$ edition. John Wiley \& Sons, 2013.

[20] D. Vasiljevic, "Better logistics and maintenance - life cycle integration and digital interactive manuals point towards the future," Industrial Engineer, pp. 37-41, April 2013.

[21] B. Scholz-Reiter, J. Kolditz, and T. Hildebrandt, "Engineering autonomously controlled logistics systems," Int. J. Production Research, vol. 47, no. 6, pp. 1449-1468, 2009.

[22] The International Society of Logistics. URL: http://www.sole.org/ SOLE, 2014.

[23] CLEP Council of Logistics Engineering Professionals. URL: http://logisticsengineers.org/

[24] G. D. Taylor, Logistics Engineering Handbook, CRC Press, 2008.

[25] J. L. Sutherland, "Logistics from a historical perspective," in Introduction to Logistics Engineering, G. D. Taylor, Ed. CRC Press, 2009.

[26] M. Jones, D. Lohrmann, and T. Surabian, Logistics Engineering Perspective. Enabling logistics transformation while reducing costs, Booz Allen Hamilton Inc., 2009.

[27] D. Sanford, "Functional experts for campaign planning: how does the air force develop logisticians to satisfy the operational level of war?," Air Force J. Logistics, vol. 34, is. 3/4, pp. 93-103, Fall/Winter 2010.

[28] J. Miebach and D. Bühring, Supply Chain Engineering: Die Methodik integrierter Planung in der Logistik, Springer, 2010.

[29] C. Shen and C. Chou, "Business process re-engineering in the logistics industry: a study of implementation, success factors and performance," Enterprise Information Systems, vol. 4, no. 1, pp. 61-78, 2010.

[30] L. Y. Zhou, "Study on business process reengineering for Chinese traditional logistics enterprises," Chinese Business Review, 6 (2), pp. 69-73, 2007.

[31] Systems Engineering Guide. The MITRE Corporation, 2014.

[32] What is Systems Engineering? International Council on Systems Engineering INCOSE, 2014. URL: http://www.incose.org

[33] Guide to the Systems Engineering Body of Knowledge (SEBoK), R. D. Adcock, Ed. Hoboken, NJ: The Trustees of the Stevens Institute of Technology, 2014. URL:

[34] http://www.sebokwiki.org/w/index.php?title=Guide to the Syste ms_Engineering_Body_of_Knowledge_(SEBoK)\&oldid=49810

[35] T. L. J. Ferris, "Comparison of systems engineering competency frameworks," $4^{\text {th }}$ Asia-Pacific Conference on Systems Engineering (APCOSE), Systems Engineering: Collaboration for Intelligent Systems, pp. 1-9, Taiwan, 3-6 October 2010.

[36] D. Cowper, S. Bennison et al, Systems Engineering Core Competencies Framework, Folkestone, UK: International Council on Systems Engineering UK Advisory Board, 2005.

[37] MITRE Systems Engineering Competency Model. Version 1.13E, The MITRE Corporation, 2007.

[38] NASA System Engineering Competencies - Academy of Program, Project and engineering Leadership, Washington, 2009.

[39] J.Holt and S. Perry, A Pragmatic Guide To Competency. Tools, framework and assessment, BSC - The Chartered Institute of IT, 2011.

[40] A.Patil and G. Codner, "Accreditation of engineering education: review, observations and proposal for global accreditation," European J. Eng. Education, vol. 32, no. 6, pp. 639-651, December 2007.

[41] H. L. Davidz and D. J. Nightingale, "Enabling systems thinking to accelerate the development of senior systems engineers," $J$. Systems Eng., vol. II, no. 1, pp. 1-14, 2008.

[42] C. Wasson, "System engineering competency: the missing course in engineering education," $119^{\text {th }}$ ASEE Annual Conference and Exposition, American Society for Engineering Education, 2012.

[43] The Designated Logistician Program, SOLE, 2005.

[44] European Qualification Standards for Logistics Professionals, Brussels: ELA European Logistics Association, 2014.

[45] International Diploma in Logistics and Transport. Standards of Knowledge and Competence, CILT - Chartered Institute of Logistics and Transport, 2006.

[46] Distribution and Logistics Managers Competency Model, APICS - The Association for Operations Management, 2014.

[47] F. Mistree et al, Personalized engineering education for the twenty-first century, in Curriculum Models for the $21^{\text {st }}$ Century. Using Learning Techniques in Higher Education, M. Gosper and D. Ifenthaler, Eds. New York: Springer, 2014.

[48] T. Niine and O. Koppel, Competence in logistics - designing a meta-model of logistics knowledge areas, in DAAAM International Scientific Book. Vienna: DAAAM International, 2014, pp. 543556.

\section{AUTHORS}

T. Niine is a lecturer at Tallinn University of Technology, Estonia (e-mail: tarvo.niine@ttu.ee)

O. Koppel, ING.PAED.IGIP, is a visiting professor and acting head of the Chair of Transportational Logistics at Tallinn University of Technology, Estonia (e-mail: ott.koppel@ttu.ee)

This article is an extended and modified version of a paper presented at the EDUCON2015 conference held at Tallinn University of Technology, Tallinn, Estonia, 18-20 March 2015.Submitted 09 March 2015. Published as resubmitted by the authors on 31 March 2015. 